\title{
Confiança no Comércio Eletrônico e a Próteção do CONSUMIDOR (UM ESTUDO DOS NEGÓCIOS JURÍDICOS DE CONSUMO no comércio eletrônico) por Claudia lima Marques*
}

\author{
Resenha Bibliográfica por \\ Maria Paula All*:
}

Nadie pone en duda que el DIPr está suftiendo la repercusión y las consecuencias de los efectos de la globalización ${ }^{1}$ y que este fenómeno incide directamente en su objeto, de manera tal que resulta necesatio buscar tespuestas adecuadas en función de la nueva realidad a regular. Se visualiza un panotama en el que la presencia de actores, fuerzas, estructuras, procesos, unidos a la creciente internacionalización de la economía, ha generado un "campo fértil" para la multiplicación de las relaciones comerciales que vinculan a más de un territorio y que, por ende, ponen en contacto una multiplicidad de sistemas jurídicos. Tales hechos, desde el ángulo de mira contractual, requieren de un análisis serio y profundo y exigen muchas veces el desarrollo coordinado de políticas entre los Estados y la elaboración de reglas internacionales que respondan verdaderamente a las necesidades de la región y de cada uno de los países que la forman.

Se ha afirmado que "en el DIPr se están moviendo los cimientos y no sólo porque hay un derecho material emergente, sino porque hay una tremenda dificultad de localización en función de la globalización y a través, sobre todo, del uso de la informática para la creación de actos y negocios. Particularmente los del derecho económico, tanto comercial como

- Lima Marques, C., Confiança no comércio eletrônico e a proteção do consumidor (um estudo dos negócios jurídicos de consumo no comércio eletrônico), São Paulo, Revista dos Tribunais, 2004, 544 pp.

* Profesora de Derecho Internacional Privado, Facultad de Ciencias Jurídicas y Sociales, Universidad Nacional del Litoral, Argentina.

1 Véase J. E. Faria, El derecho en la economía globalizada, Trotta, Madrid, 2001, p. 49 y P. A. de Miguel Asensio, "El Derecho internacional privado ante la globalización", AEDIPr, t. 1, 2001, p. 58.

z D. P. FERNANDez ARroYo, "Acerca de la necesidad y las posibilidades de una Convención interamericana sobre competencia judicial en casos de derecho internacional privado", Libro Homenaje a Didier Opertti Badán (en prensa), véase especialmente pto. $V$. Conclusiones y propuestas. 
financiero"3. La expansión de las redes digitales impacta no sólo en la conducta de los operadores jurídicos sino que también influye en la configutación de las relaciones privadas, modificando muchas veces su alcance. La realidad social vertiginosamente se ha transformado y ha generado que la ordenación de los conflictos de intereses vinculados con Internet plantee retos al ordenamiento jurídico, de forma tal que el mismo debe ser en muchos aspectos revisado e interpretado a fin de lograr el equilibrio (o la compatibilidad) entre la seguridad jurídica y la difusión generalizada de los recursos que brinda la red ${ }^{4}$. La obra que reseñamos, Confianza no comércio eletrônico e a protę̧ão do consumidor (um estudo nos negócios jurídicos de consumo no comércio eletrônico) se enmarca en este contexto y prioriza en todo momento la defensa del consumidor, el cual aparece la mayor parte de las veces como el "protagonista olvidado" de las relaciones juridicas.

La autora Cláudia Lima Marques, profesora titular de la Universidad Federal de Río Grande del Sur, Brasil, y coordinadora del Programa de Postgrado en Derecho de dicha facultad, plantea en la introducción de su trabajo una definición de comercio electrónico y parte del análisis del "nuevo paradigma de confianza". Centrada en el hecho de la existencia de un espacio nuevo en el mundo constituido por Internet, las redes electrónicas y de telecomunicación de masa, la pregunta que la anima es cómo conquistar la confianza de los consumidores en ese "instrumento nuevo de hacer comercio" y proteger, a su vez, las expectativas normarivas y legitirnas de las partes débiles de los contratos. Señala que tiene la certeza de que el derecho puede ayudar a establecer este nuevo paradigma, a conseguir la necesaria protección calificada del usuario-lego a través de exigencias de mayor información y transparencia, más cooperación en cuanto a las posibilidades de arrepentimiento y reflexión, mayor seguridad en las formas de pago por medios electrónicos y cuidado con relación a los datos recogidos. En su opinión, la "confianza" es el nuevo paradigma necesatio para dar un paso adelante, es decir, para adaptar nuestro actual derecho del consumidor a este nuevo modo de comercio. Lima Marques acepta, en el libro, una calificación amplia de comercio electrónico, de forma tal de abarcar con esta denominación todos los contratos y todas las fases del negocio jurídico entre el productor y su cliente.

En todo momento la autora rescata las enseñanzas de Erik Jayme, para quien el mundo pos-moderno está caracterizado por la comunicación y por no tener más fronteras. No son solamente los medios tecnológicos los que permiten un cambio rápido de información e imágenes, sino también la voluntad y el deseo de comunicarse con ottas personas. La ubicuidad, la velocidad y la libertad, características del tiempo pos-moderno, encuentran en

3 D. OमERT' BADAN, "El Derecho internacional: una agenda renovada", Jornadas de Derecho Internacional, Montevideo, Organización de los Estados Americanos - Secretaria General, 1999, p. 302.

4 P. A. pe Miguel Asensio, Derecho prizado de internet, $2^{*}$ ed. actializada, Madrid, Civias, 2001, p. 23. Se ha señalado en este sentido que aparición de la virtualidad no exige una revolución copernicana, sino básicamente una tarea de adpución. Asi, J. A. Gratia, El Derecho internacional privado del comercio electrónico, México, Thernis, 2003 , p. 3.

5 JM. ARrgeti, "La protección de los consumidores y el Mercosur", Revista de Direito do Consumidor, vol. 2,1992, p. 126. 
este nuevo medio de comunicación y comercio que es Internet un lugar de privilegio. E1 consumidor / usuario, como parte de la relación, experimenta en este ámbito una nueva vulnerabilidad, y de ahí la necesidad y la importancia de revisar las líneas de "buena fe" y de "confianza" en las relaciones contractuales y adaptarlas al comercio electrónico.

La hipótesis de trabajo de la cual parte Lima Marques es que el nuevo lenguaje visual, fluido, rápido, agresivo, seudo-individual y masificado de los negocios jurídicos de consumo a distancia por Internet propone desafios serios para el derecho privado, en especial para el derccho del consumidor. La autora destaca que el uso del medio virtual o la entrada en una cultura visual lleva a una pérdida de significado o de eficiencia del principio de buena fe que guió al derecho privado y, en especial, al detecho del consumidor en el siglo XX. Para alcanzar la necesatia eficacia de los instrumentos jurídicos en estos "tiempos virtuales", para adaptar el derecho del consumidor a este nuevo paradigma, el derecho privado debe necesariamente evolucionar y redescubrir el principio de confianza.

Como lo señala Jayme, la comunicación y la información son las señales más importantes de nuestros tiempos pos-modernos. El derecho debe proteger equitativamente al más débil, debe ser capaz de valorizat la información declarada en el medio electrónico, tener en cuenta el déficit informativo de los legos sin importar cuál sea su nacionalidad o territorio. Coincidimos plenamente con que el comercio electrónico no puede ser un "local" sin ley y sin garantías para los legos. El desafio que se presenta merece un análisis teórico profundo. De alli entonces que la obra de Lima Marques adquiera una profunda importancia, no sólo por los desarrollos teóricos y por las pertinentes citas jurisprudenciales que fundamentan sus afirmaciones, sino también por la labor de descripción y exhaustivo análisis de la normativa vigente a nivel nacional, regional e internacional.

La obra que reseñamos se encuentra estructurada en dos partes: la primera referida a la teoría básica de los negocios jurídicos de comercio electrónico de acuerdo a una visión de derecho material interno - o, como prefiere denominarla la autora siguiendo a Tito Ballarino, "análisis del contrato de comercio elecrrónico en un ambiente interno"-, y la segunda, referida al Derecho internacional privado para los negocios juridicos de comercio electrónico con consumidores o, dicho de otra forma, "análisis en un ambiente internacional".

En la primera parte, sin la pretensión de realizar una teoría general de los contratos de comercio electrónico, efectúa inicialmente observaciones teóticas sobre las características más originales y pos-modernas del comercio electrónico que pueden influenciar el derecho privado o paraestatal. De alli el nombre de "teoría básica".

El entorno digital - propio de la llamada sociedad de la información - provoca un impacto mundial y el alcance global de este medio acarrea "nuevos desafíos" para el mundo jurídico. La finalidad de esta primeta parte del libro es identificar y analizar los desafíos (de "deconstrucción" y "reconstrucción") que el fenómeno de la contratación electrónica propone para el derecho privado en general y su regulación (capítulo 1), para sólo en un segundo momento enfrentar la casuística de los contratos de comercio electrónico con consumidores 
y las reglas de contratación a distancia (capítulo 2). La autora agrupa y analiza en el primer capítulo los "desafios negativos" o de deconstrucción propuestos por los negocios de comercio electrónico (fenómenos posmodernos sociológicos), es decir, la despersonalización de la relación jurídica y el silencio en ese diálogo virtual, la desmaterialización del medio de contratación, del objeto y de los vicios, la desterritorialización, la falta de reglamentación, la atemporalidad de la contratación electrónica y la desconfianza de los consumidores en el comercio electrónico. Lima Marques remarca en este primer capítulo - y lo seguirá haciendo a lo largo de la obra - que no hay nada más pos-moderno que las relaciones virtuales, desmaterializadas, que involucran a una plutalidad de agentes, típicas de la sociedad de la información, fluidas, rápidas, visuales, interactivas, simultáneas, despersonalizadas y, a su vez, globalizadas y culturalmente niveladas, atemporales, internacionales, desterritorializadas, típicas de una economía post-fordista, de servicio, de hacer, de lo inmaterial, lo desregulado, lo tercerizado, lo individual. Todos estos adjetivos no son casuales ni están usados al azar por la autora, sino que marcan, de algún modo, las dificultades que se presentan y ponen en evidencia la ineficacia del uso de los instrumentos tradicionales de protección de los consumidores.

En el capítulo 2 estudia los "desafíos positivos", analizando los primeros instrumentos y reglas desarrollados para combatir los mencionados retos negativos o, dicho de otra forma, para "reconstruir la dogmática deconstruída". Tal como lo plantea la autora, los drásticos cambios en la manera de contratar pueden ser vistos como oportunidades o como riesgos. Si, de un lado, poco acceso a Internet representa una nueva manera de discriminación de los más pobres, mucho acceso a Internet puede llevar a una estandarización mínima de la cultura y a una pérdida de la diversidad cultural.

En el capítulo 3 se aborda la problemática de los negocios jurídicos de comercio electrónico con consumidores. La autora advierte que, así como en el primer capítulo de la obra realizó algunas observaciones teóricas sobre las caracrerísticas más originales y posmodernas del comercio electrónico, ahora intenta profundizar más en la práctica a fin de analizar detalladamente estas reglas $\mathrm{o}$, en su ausencia, los principios y cláusulas generales que pueden ayudar al aplicador del derecho a resolver los casos concretos que se plantean. Así, identifica y describe las prácticas comerciales, los contratos y los problemas más comunes en el comercio electrónico con consumidores, para en un segundo momento dedicarle atención a las especialidades de la ejecución de estos negocios y su régimen jurídico. Las "bases y sugerencias del derecho del consumidor para la reconstrucción de la confianza en el comercio electrónico" se encuentran plasmadas en el capítulo 4.

La segunda parte del libro, titulada "Un derecho internacional privado para los negocios jurídicos de comercio electrónico con consumidores", contiene extractos actualizados del XXVII Curso de Derecho internacional del Comité Jurídico Interamericano, "La protección del consumidor: aspectos de derecho privado regional y general", que la profesora Lima Marques dictó en Río de Janeiro en el año 2000. A lo largo de cuatro capítulos se refiere al estudio y análisis de la internacionalidad del comercio electrónico, las reglas actuales de DIPr, 
las atinentes al proceso civil internacional y las normas "deseables o necesarias" para el comercio electrónico con consumidores. Teniendo en cuenta la actual apertura del mercado brasileto en el marco del comercio internacional, reflexiona sobre la necesidad y oportunidad de que el Detecho del consumidor contenga nuevas normas tuitivas especiales; así, la protección ya concedida por el Código de Defensa del Consumidor brasilero sería complementada con los métodos directos y conflictuales del DIPr actual.

En palabras de la autora, la protección del consumidor pasivo en una telación de consumo internacional o pluriconectada constituye un interesante desafío para el derecho actual ya que involucra preocupaciones juridico-políticas de doble naruraleza: de un lado, el derecho nacional se preocupa en mantener un nivel material de prorección de los consumidores y, de otro, con la apertura de los mercados y la libre concurrencia, la idea maestra es la facilitación del comercio internacional y la preservación de la libertad de los consumidores de escoger con quién contratar en un mercado globalizado, no habiendo mucho espacio para intervenciones rerritorialistas o xenófobas. Así, la respuesta debe buscarse en el diálogo entre la finalidad de tutelar al sujeto más débil del derecho del consumidor nacional y la finalidad de la justicia y la armonía internacional del DIPr. Ahora bien, como claramente señala la profesora Lima Marques, este diálogo supone tolerancia, apertura para opiniones y visiones plurales del mismo fenómeno. Entre los rasgos característicos del DIPr de nuestros días se alude, entre otros, al marcado protagonismo del conflicto de jurisdicciones sobre el conflicto de leyes, la preponderancia de normas materiales y el avance del soft law, la necesaria distinción que debe hacerse entre las normas de DIPr de fuente interna y las de fuente internacional, la incorporación de valores en la reglamentación de las relaciones de tráfico externo. Las relaciones no deberían plantearse en términos de exclusión sino de diálogo ${ }^{6}$, diálogo que debe ser permanente y que -como afirma Jayme- caracteriza la fase posmoderna del $\mathrm{DIPr}^{7}$; es cierto, sin embargo, que dicha comunicación si bien resulta indispensable, muchas veces se torna rarea difícil'.

La protección de los más débiles, de los vulnerables por medio de la dogmática actual del DIPr presenta una serie de facetas, muchas veces no analizadas (o no profundizadas suficientemente). Las relaciones asimétricas que muchas veces se entablan entre los sujetos y que se traducen en un notable desequilibrio para una de las partes genera sin lugar a dudas la

6 E. JAYME, "Identité culturelle et intégration: le droit international privé postmoderne. Cours général de droit international privé", Recueil des Cours, t. 251, 1995, pp. 61 y 259.

"E. JAYME, "Directo Internacional Privado e Integração: as Convenções Européias", en: P. B. Casella / N. De Ataujo (cootds.), Integração Junidica Interamericana, as Convençóes Interamericanas de Direito Internacional Privado(CIDIPs) eo direito brasileiro, Säo Paulo, LTR, 1998,p. 116.

8 D.P. FERnÁndez ARroYo, "Globalización y Derecho: el caso de la reglamentación internacional de las garantías mobiliarias", en: A.L. Calvo Caravaca / P. Blanco-Morales Limones, Globalización y Derecho, Madrid, Colex, 2003, pp. 298.303, aunque referido al análisis de las garantías mobiliarias, similar planteo puede ser traspolado al ámbito contractual. 
necesidad de que exista una tutela efectiva y que la misma se positivice a través de normas jurídicas claras. El interés de proteger al agente económico más débil se ha puesto de relieve en los esfuerzos de armonización de la legislación nacional de la Unión Europea y en el ámbito de MERCOSUR, así como los estudios realizados por el NAFTA y por otros bloques de cooperación e integración regional americanos.

Las normas legales nacionales deberían ser suficientes para proteger al consumidor de este nuevo mercado sin fronteras al mismo tiempo que no deberían ser usadas por los países como barreras a la libre circulación de productos o servicios de los países integtados o que pertenecen a una zona de libre comercio o a una unión aduanera. Ahora bien, las normas nacionales que regulan el comercio internacional, así como el derecho uniforme del comercio internacional o la moderna lex mercatoria generalmente no se preocupan en proteger al consumidor sino que, por el contrario, tratan de excluir estos contratos de su ámbito de aplicación. La realidad de la mayoría de los países de las Américas muestra que las leyes nacionales de protección del consumidor - de derecho civil y de derecho comercial - y las normas generales raramente poseen reglas de DIPr especiales para la tutela efectiva de los contratantes más débiles, de las víctimas de accidentes por productos o servicios defectuosos, de los turistas, de los que reciben la publicidad y el marketing agresivo y emocional de estos tiempos. Las normas nacionales de DIPr de estos países son, en líneas generales, antiguas. De allí que la labor de armonizar (o unificar) normas materiales de defensa del consumidor constituye una tarea teórica difícil que necesita un mandato claro en cuanto a los objetivos a alcanzar y el nivel de protección deseado.

La autora plantea que el sistema interamericano está claramente abierto para el comercio internacional y la regionalización, pero posee un ordenamiento jurídico con lagunas e insuficiente para proteger a los agentes económicos más débiles de ese mercado. Una evolución sería necesaria y, en este sentido, sugiere la elaboración de una CIDIP sobre protección al consumidor en dos situaciones especificas: la del consumidor turista y la del consumidor que contrata a distancia, sea por medios tradicionales o electrónicos. Lima Marques se explaya, en el primer capitulo de esta segunda parte, sobre la oportunidad y la necesidad de una Convención interamericana de DIPr sobre la ley aplicable a los contratos y relaciones de consumo por medio electrónico. Hace hincapié en la oportunidad que se presenta para una "nueva convención regional específica" y efectúa una reseña histórica de la protección del consumidor en las Américas, remarcando la insuficiente protección nacional del consumidor en el DIPr americano y en las convenciones generales sobre comercio de mercadenas. El capítulo 2 se refiere a la falta de protección especial del consumidor en las normas de DIPr interamericanas y analiza las conexiones actuales y su inadecuación para la protección del consumidor.

Siguiendo la línea de Jayme, Lima Marques sostiene que el DIPr pos-modemo conseguiría equilibrar y tepresentar al mismo tiempo las fuerzas contradictorias sociales y económicas de nuestra época, del individualismo posmoderno y de una identidad cultural exacerbada, la fuerza irresistible de la aproximación y regionalización económica, de espacios supranacionales de integración y de un libre comercio globalizado. La protección del 
consumidor se inserta en este contexto como una válvula de escape de los conflictos posmodernos, pues representa juridicamente la garantía de un standard mínimo de seguridad y adecuación de servicios y productos nacionales o importados, comercializados en los mercados globalizados. Representa políticamente un compromiso con la lealtad del mercado, asegurada en una visión macro por el derecho de la concurrencia y en una visión micro, por el derecho del consumidor. Por fin, socialmente, procura equilibrar el revival de la autonomia de la voluntad, del papel del individuo para determinar soberanamente sus relaciones privadas, económicas y de consumo y el revival de los derechos humanos, una vez que, recibiendo protección del Estado y siendo derecho fundamental de los ciudadanos de muchos países, el derecho del consumidor es un derecho humano de nueva generación.

En el capírulo 3 la autora concreta las bases para la elaboración de normas nacionales especiales y de una Convención de la OEA sobre la ley aplicable a los contratos de consumo y relaciones de consumo por medio electrónico. La propuesta de Lima Marques no incluye los aspectos de proceso civil internacional para no duplicar los esfuerzos actualmente realizados por UNIDROIT y por la Convención de La Haya en este sentido, pero nada impide -según la autora que con la colaboración de otros especialistas se amplíe ese proyecto. Se analizan aquí las reglas especiales y las convenciones para la protección del consumidor, analizando particularmente las enseñanzas de la experiencia de la Unión Europea y del MERCOSUR. Con respecto a MERCOSUR analiza, por una parte, las tentativas frustradas de unificación y armonización de normas materiales de protección del consumidor y, por orra, las normas de DIPr y las normas procesales internacionales sobre protección del consumidor en el ámbito mercosureño. El último capítulo de esta segunda parte está dedicado a las especificidades del consumo internacional y la ley brasilera. Se abordan aquí dos cuestiones fundamentales: la primera referida al régimen de las relaciones de consumo internacional en Brasil y la caracterización de las normas de protección contractual a distancia del Código de defensa del consumidor como normas de aplicación inmediata por la doctrina y la jurisprudencia brasileras; la segunda tiene que ver con la sugerencia de una futura CIDIP y nuevas normas de DIPr brasileñas.

"El DIPr es un derecho vivo, en constante evolución y, en consecuencia, adaptable a los cambios del nuundo actual"'. El tema del comercio electrónico y la necesaria protección del consumidor como parte débil de los negocios adquiere ribetes especiales en el momento actual, máxime cuando de cara a la CIDIP VII no sólo Brasil sino otros países han sugerido que tales tópicos formen parte de la agenda y del temario de la Conferencia. En este sentido, la obta reseñada se constituye en un punto de referencia ineludible. Una de sus principales virtudes es, precisamentc, encarar el tratamiento de esta materia desde la óptica nacional c internacional, de manera tal que le permite allector visualizar un panorama claro y estructurado

" T. B. DE MAEkEj, "La codificación interamericana en materià de Derecho internacional privado en el contexto universal y regional", Libro Homenaje a Haroldo Valladão, Universidad Central de Venezuela, Caracas, 1997, p. 160. 
de la situación normativa actual. Sin lugar a dudas, el entorno digital y la globalización misma tienen dinámicas y asumen formas contradictorias: homogeneización versus heterogeneización, localismo y regionalismo contra mundialismo, globalización económica versus carencia de globalización política y juridica, globalización homogeneizante de la cultura contra reivindicaciones de la autonomía e identidad socioculturales. ${ }^{10} \mathrm{~A}$ pesar de los obstáculos y dificultades de distinta índole que han debido enfrentar las CIDIPs, la finalidad tectora de elabotar normas de DIPr modernas y ajustadas a las exigencias actuales de los Estados que componen la OEA sigue, con el transcurso de los años, manteniéndose incólumne. Ahora bien, lo que resulta absolutamente necesario - y se ha puesto en evidencia principalmente en la CIDIP VI - es un mayor compromiso, especialmente de algúnos países latinoamericanos, en la elaboración y discusión de los documentos de trabajo. Por ello, la inclusión en la obra de Lima Marques de una "Propuesta de CIDIP" sobre ley aplicable a "algunos contratos y transacciones con consumidores" es realmente bienvenida y creemos que constituye el resultado decantado de una larga investigación y producción científica sobre el tema que la autora ha llevado a cabo a través de los años.

A medida que los acontecimientos se suceden, que la integración como fenómeno económico y jurídico produce importantes y profundos efectos, la teotía y la reglamentación del DIPr deben avanzar en el sentido de poder brindar y desarrollar instrumentos y herramientas que permitan resolver de manera integral las desavenencias que presentan los casos jusprivatistas multinacionales. Resulta vital y necesario entonces que los textos juridicos resulten apropiados a la realidad actual; en este sentido, creemos y compartimos la idea de que la CIDIP ha sido, y debe seguir siendo, el escenario natural para "fabricar" tales textos".

La obra de la Profesora Lima Marques constinuye un valioso aporte no solamente con relación al comercio electrónico y la protección de la parte típicamente débil del contrato, sino también para la "reconstrucción del DIPx"; como ella misma planteara en su respuesta al "cuestionario sobre el futuro de la CIDIP"12, esa reconstrucción debe hacerse a través de la pluralidad de métodos, de su tolerancia intrínseca y de su capacidad de respetar las diferencias

"M. KAplaN, "Estado y globalización. Regulación de flujos financieros", en: M. Kaplan / I. Manrique Campos (coords.), Regulación de flujos financieros internacionales, México, Insticuto de Investigaciones Económicas / Instituto de Investigaciones Juridicas, Universidad Nacional Autónoma de México, $2001,58$.

1) Así, D.P. FERnÁndez ARroyo, Derecho internacional privado interamericano. Evolución y perspectivas, México, Universidad Anáhuac del Sur / Miguel ängel Porrúa, 2003, p. 134. Véase también del mismo autor la "Introducción" a su obra Derecho Internacional Privado (Una mirada actual sobre sus elementos esenciales), Córdoba, Advocatus, 1998, especialmente el punto 2, $2^{\circ}$ Párrafo, p. 17.

12 El 22/05/2002 el Comité Jurídico Interamericano -con la asistencia de la Secretaria de Asuntos Jurídicos- distribuyó entre un amplio grupo de académicos, juristas y expertos legales americanos y de otros países un "Cuestionario sobre el futuro de la CIDIP". Véase la respuesta de la profesora Lima Margues, especialmente el punto 8. 
culturales y juridicas de los países de las Américas. Obras como las reseñadas ponen el acento precisamente en la concientización de los detechos de las partes vulnerables. En este matco, seria deseable - y valorable - que pudiésemos refutar aquella frase de Ernesto Sábato de que "el mundo de la técnica y la informática, que supuestamente nos iba a acercar unos a otros, significó para la inmensa mayoría, un abismo insalvable..." ${ }^{3}$. El trabajo de Lima Marques no solamente acerca e interioriza al lector sobre el tema, sino que genera una profunda inquietud acerca de la regulación positiva y la manera en la que pueden incluirse valores sustanciales de tespeto y dignidad humana

t3 E. SABato, Antes del fin. Memorias, Buenos Aires, Seix Bartal, 1999, p. 127. 